\title{
Laboratory test of equivalent material as artificial ground
}

\author{
Anton Sokornov ${ }^{1 *}$, Evgeny Shaposhnikov ${ }^{1}$, and Alexander Konkov ${ }^{1}$ \\ ${ }^{1}$ St. Petersburg State Transport University, Moskovsky 9, St-Petersburg, 190031, Russia
}

\begin{abstract}
Appearing in the scientific literature in the second half of the twentieth century, the term "artificial ground" currently does not cover the entire range of geological formations associated with human activity. The authors of the article proposed a classification of artificial grounds, as well as put forward a number of considerations for strength tests of special group of artificial grounds - the equivalent materials for laboratory modeling.
\end{abstract}

\section{Introduction}

In the second half of the twentieth century, the term "artificial ground" in Soviet scientific literature was identified as technogenic geological formation resulting from crushing, loosening, mixing and transportation of rocks for the construction of building foundations and structures, and as a result of the metallurgical and chemical production (dumps of ashes and slags) [1, p. 112].

Since the mid-eighties the world has seen the growth of mass production of plastic products, resulting in a significant amount of non-biodegradable waste (Fig. 1). The main part of them falls on organized landfills, which at the end of their service life undergo the process of reclamation, or form chaotic landfills, where they accumulate in the form of the so-called "cultural layer".

It is obvious from the above that there is a need to expand the concept of "artificial ground", in its scientific classification and in determining the approaches to its laboratory tests.

\section{Classification of artificial grounds}

The authors propose to classify artificial grounds into two categories - created not purposefully and purposefully (Fig. 2, 3).

The first category should be primarily attributed to grounds resulting from natural and urban pollution - the "cultural layer" and the so-called "plastiglomerate" [2] - caught in the oceans, plastic waste decomposes under the solar radiation on individual particles and mixes with natural sediments. Also in this category it necessary to include specific geological formations that arise subsequently "man-made disasters": military operations, accidents, explosions, etc. These formations can be relatively safe conglomerates of concrete, brick,

*Corresponding author: scarlunch@mail.ru 
wood and steel, as well as pose toxic or radiation hazards, such as oil spills in oil rig accidents, or corium formed in nuclear power plant explosions.

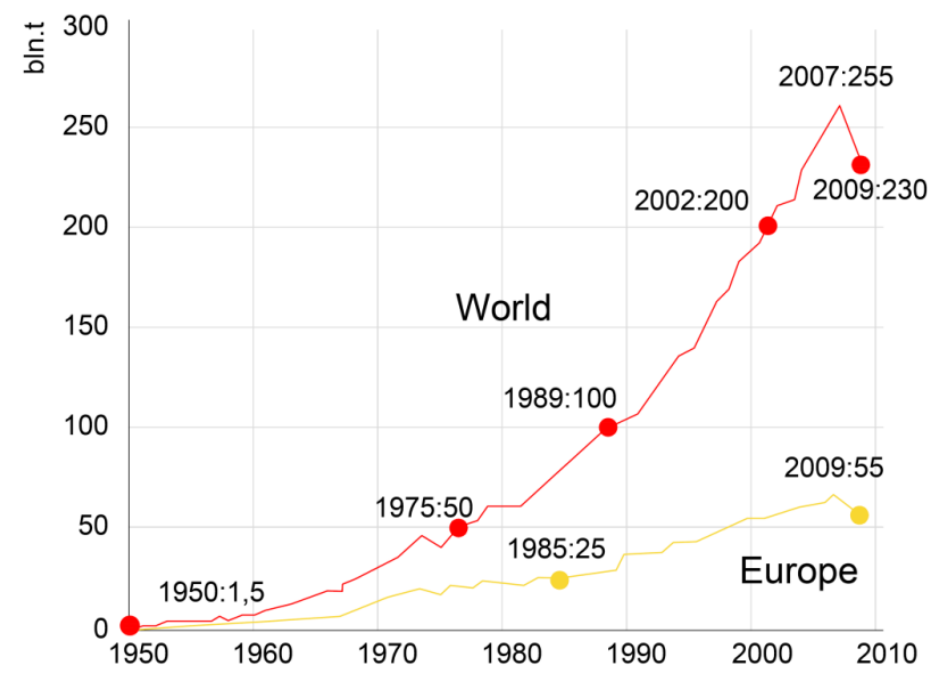

Fig. 1. Dynamics of plastic production

The category of artificial grounds created purposefully firstly should contain technogenic grounds, including landfills as the results of industrial activities (waste recycling). Secondly, this category of artificial grounds can include specific equivalents of real grounds, made from a mixture of different materials for scientific modeling of ground massifs [3]. Despite the lack of "geological significance" of this type of ground, it is important for the construction sciences and require a special approach in terms of laboratory tests.

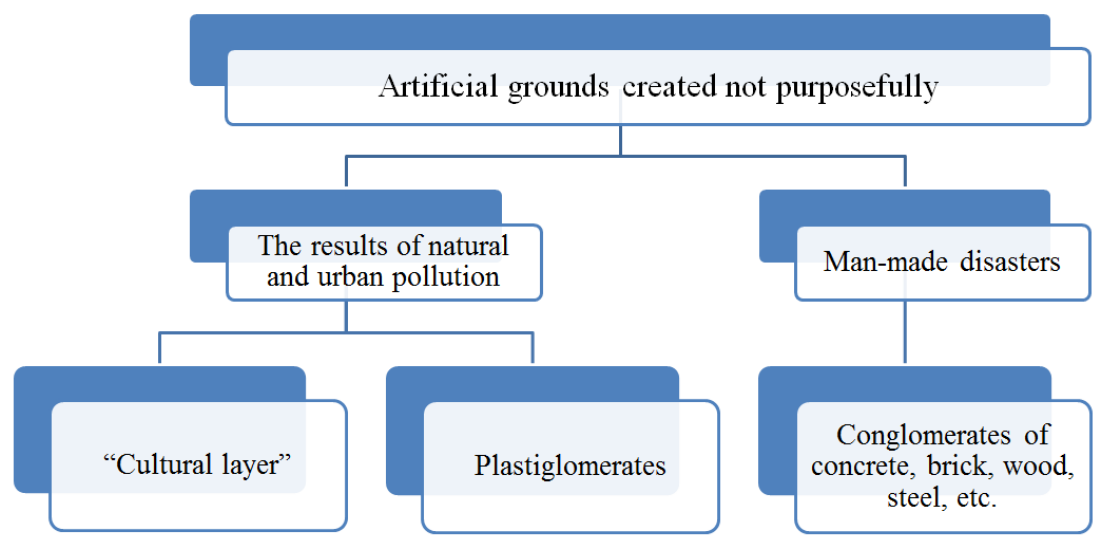

Fig. 2. Classification of artificial grounds created not purposefully

\section{Tests of equivalent material}

For many years the Department "Tunnels and subways" conducted scientific experiments on physical modeling by equivalent materials $[4,5,6,7,8]$. This method is based on the replacement of natural grounds and construction materials with artificial materials in the model so that indicators of physical and mechanical properties are in certain ratios with similar indicators of the same properties of nature. These relations are determined on the 
basis of the general regulations of Newton's theory of mechanical similarity [3] and provide an analogy of the processes occurring in nature and in the model under the gravitational forces influence.

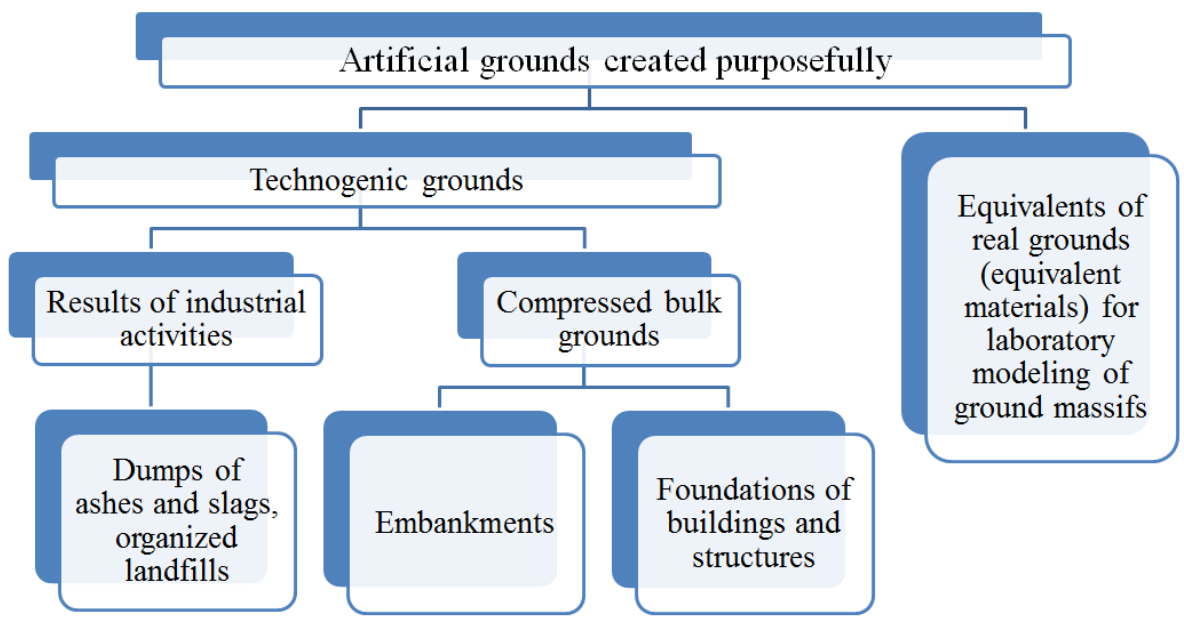

Fig. 3. Classification of artificial grounds created purposefully

Currently, work is underway on the modeling of subway structures in the ground massif composed of upper Kotlin clays. Defining physical and mechanical characteristics of grounds of nature and of the model are: internal friction angle $\varphi$, cohesion $\mathrm{C}$ and the deformation modulus E. In accordance with the law of mechanical similarity required characteristics of the ground in model can be expressed through the characteristics of nature in the following way:

$$
\begin{gathered}
C_{m}=\frac{\ell}{L} \frac{\gamma_{m}}{\gamma_{n}} \mathrm{C}_{n} \\
\mathrm{E}_{m}=\frac{\ell}{L} \frac{\gamma_{m}}{\gamma_{n}} \mathrm{E}_{n} \\
\varphi_{m}=\varphi_{n}
\end{gathered}
$$

where: $C_{m}$ and $C_{n}-$ cohesion of the equivalent material of the model and of the ground of the nature, respectively;

$E_{m}$ and $E_{n}$ - deformation modulus of the equivalent material of the model and the ground of the nature, respectively;

$1 / \mathrm{L}-$ linear scale of the modeling;

$\gamma_{\mathrm{m}}$ и $\gamma_{\mathrm{n}}$ - the density of equivalent material models and ground life, respectively;

$\varphi_{\mathrm{m}}$ и $\varphi_{\mathrm{n}}$ - internal friction angle of equivalent material models and ground life, respectively.

The selection of equivalent material components was carried out taking into account the scale 1:20 according to the formulation obtained as a result of scientific research of the laboratory in the Soviet and post-Soviet periods, with some adjustments. Equivalent of upper Kotlin clays consists of the following components, mix warmed: quartz sand, mica and technical vaseline as a binder.

To determine the strength characteristics of the equivalent, a well-proven digital singleplane shear device from Ele International, UK was used (Fig. 4, 5). 


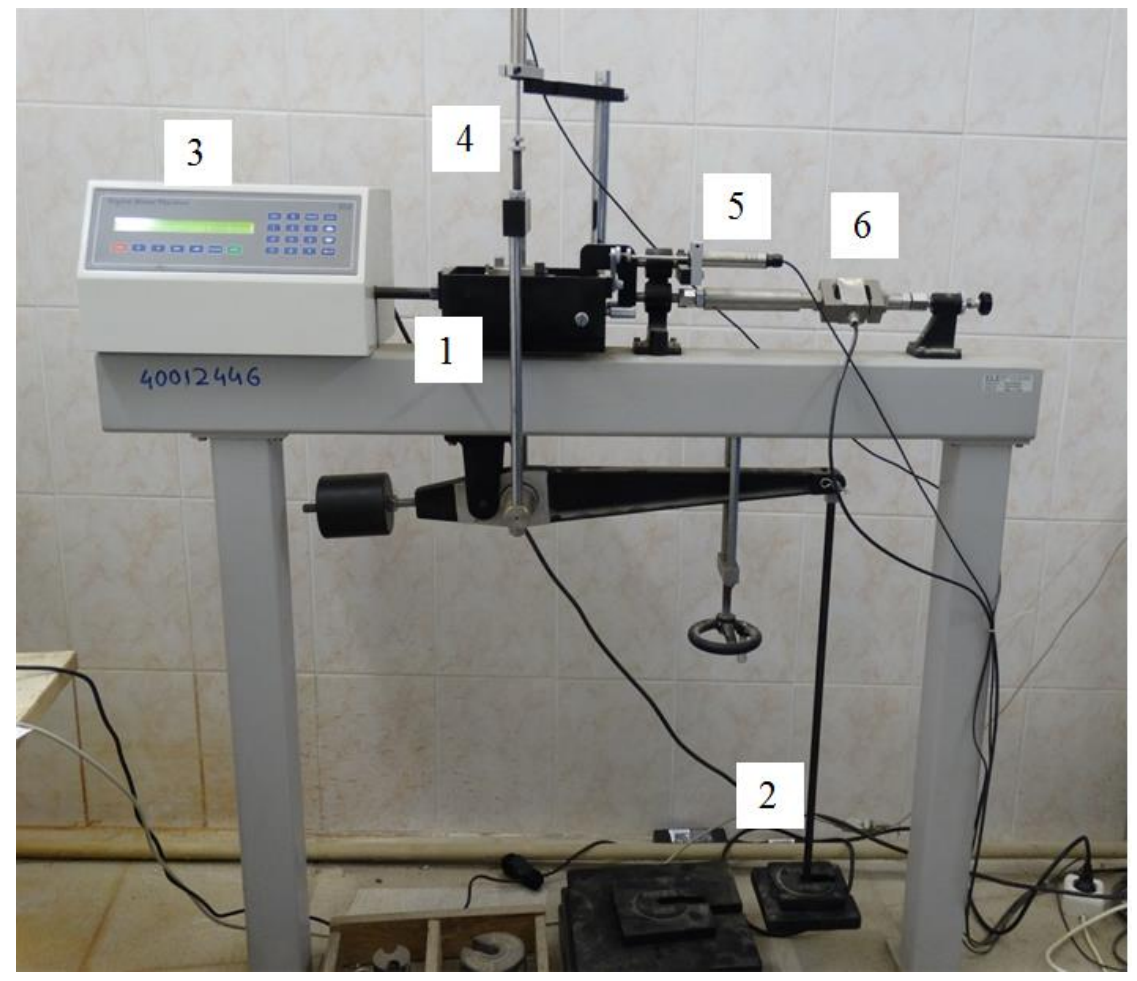

Fig. 4. Digital device single-plane shear: 1 - sliding carriage, 2 - lever weight, 3 - carriage drive, 4 vertical displacement sensor, 5 - horizontal displacement sensor, 6 -S-shaped dynamometer

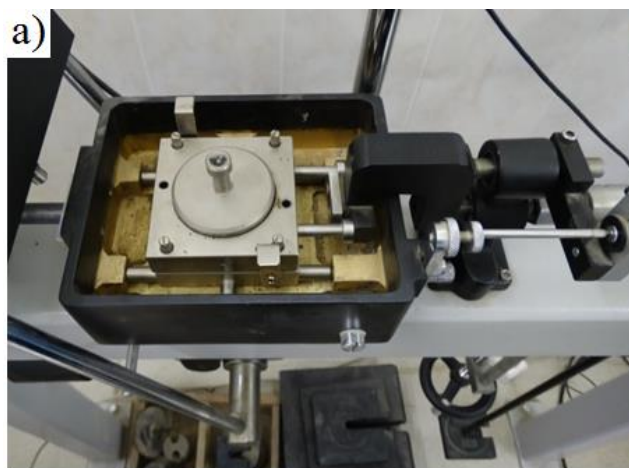

б)

Fig. 5. Equivalent material: $a$ - placed in the shear carriage, $b$ - removed after testing

The main regulatory document governing the conduct of strength tests, is GOST 122482010 [9]. In accordance with it, the ground test by single-plane shear is carried out to determine the angle of internal friction and cohesion of sands, clays and organo-mineral grounds [9, par. 5.1.1.1]. Equivalent of upper Kotlin clays is composed of $\sim 76 \%$ of sand, however, it cannot be considered as sandy ground due to the presence of binder - technical vaseline, leading to a strong decrease of the deformation modulus. While the deformation modulus of nature is $\sim 100 \mathrm{MPa}$, the required deformation modulus of the equivalent should be within $3 . .4 \mathrm{MPa}$, which is even lower than that of very soft clays $-5 . .8 \mathrm{MPa},[10, \mathrm{p} .13$, table. 1.13].

However, the equivalent cannot be considered as a cohesive ground. Despite the fact that vaseline provides compaction of the material with preservation of form, even at the slightest 
load, the equivalent crumbles into small lumpy grains. Only careful cutting of the sample from the forming tray allows achieving the preservation of the integrity of its structure.

Shear tests were carried out with a deviation from the GOST method in the value of the applied normal pressure. Instead of 100, 300 and $500 \mathrm{kPa}$ for sands or 100,150 and $200 \mathrm{kPa}$ for clays [9, table. 5.1], taking into account the scale of the simulation, the normal pressure should be applied an order of magnitude less -9.1, 16.2 and $32.0 \mathrm{kPa}$ (non-integer values are caused by the English system of measures used in the design of the device).

Fig. 6 presents the results of shear testing of equivalent material.

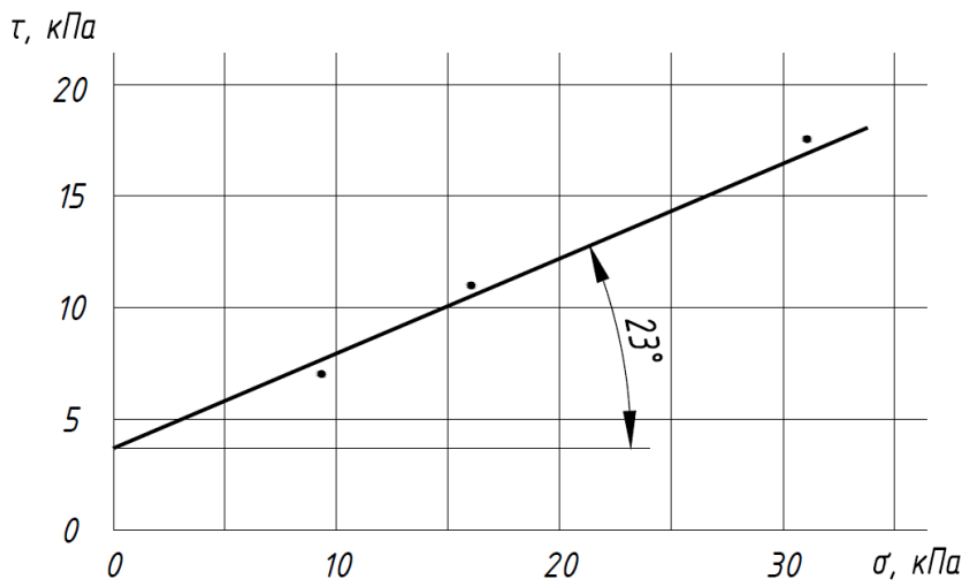

Fig. 6. Shear test results

The device capabilities also allow for an approximate estimate of the equivalent deformation modulus. The result of comparing the actual characteristics of the equivalent with the calculated ones is presented in table 1 .

Table 1. Physical and mechanical characteristics

\begin{tabular}{|l|l|l|l|l|}
\hline Physical and mechanical & \multirow{2}{*}{ of the nature } & \multicolumn{2}{|l|}{ of the model } & \multirow{2}{*}{ Error, \% } \\
\cline { 3 - 4 } characteristics & & calculated & actual & \\
\hline Density & $\gamma=2,2 \mathrm{~g} / \mathrm{cm}^{3}$ & $\gamma=1,66 \mathrm{~g} / \mathrm{cm}^{3}$ & $\gamma=1,66 \mathrm{~g} / \mathrm{cm}^{3}$ & - \\
\hline The angle of internal friction & $\varphi=23^{0}$ & $\varphi=23^{0}$ & $\varphi=23^{0}$ & 0 \\
\hline Cohesion & $\mathrm{C}=100 \mathrm{kPa}$ & $\mathrm{C}=3,77 \mathrm{kPa}$ & $\mathrm{C}=3,2 \mathrm{kPa}$ & 15 \\
\hline Modulus of deformation & $\mathrm{E}=100 \mathrm{MPa}$ & $\mathrm{E}=3,77 \mathrm{MPa}$ & $\mathrm{E}=3,2 \mathrm{MPa}$ & 15 \\
\hline
\end{tabular}

In general, the results of shear tests of the equivalent material can be concluded about the possibility of its use as an equivalent of the upper Kotlin clays.

\section{Summary}

The variety of artificial grounds, the specificity of their composition and features of physical and mechanical properties dictate the need for scientific classification and determination of approaches to their laboratory tests.

The algorithm of strength tests prescribed in GOST is not always suitable for artificial grounds. As it can be seen from the example of equivalent material tests, the scientist is required not to blindly follow the methods enshrined in the normative documentation, but a creative approach that takes into account the structure of artificial ground, its behavior under load and even the individual characteristics of the laboratory equipment used. 


\section{References}

1. E.M. Sergeev (ed.) Engineering Geology of the USSR (Moscow, Moscow University Press, Russian Platform, 1978).

2. L. Patricia, C.J. Moore, K. Jazvac, GSA Today, 24 (6), 4-8.

3. G.N. Kuznetsov, M.N. Budko, Yu.I. Vasiliev et al., Modeling of manifestations of rock pressure (Leningrad, Nedra, 1968).

4. Limanov, Yu.A. and others, Modeling tunnels by the method of equivalent materials (technical description of the exhibit), (Leningrad, LIIZhT, 1964).

5. Research report Study of the deformative and strength properties of Proterozoic clays and recommendations for their use in the design of lining of underground collectors (LIIZhT, 1976).

6. Yu.S. Frolov, A.N. Konkov, A.A. Larionov, Zapiski Gornogo instituta (2012).

7. Yu.S. Frolov, A.N. Konkov, A.A. Larionov, Promyshlennoye i grazhdanskoye stroitel'stvo, 9 (2013).

8. Y.S. Frolov, A.N. Konkov, A.A. Larionov, Transportation Geotechnics and Geoecology, TGG 2017, 673-680 (2017).

9. GOST 12248-2010 "Interstate standard. Soils. Laboratory methods for characterizing the strength and deformability"

10. M.I. Gorbunov-Posadov, V.A. Ilyichev, V.I. Krutov et al., Foundations, foundations and underground structures (Moscow, Stroyizdat, 1985). 